\title{
Efficient Emission in Halide Layered Double Perovskites: The Role of $\mathrm{Sb}^{3+}$ Substitution in $\mathrm{Cs}_{4} \mathrm{Cd}_{1-\mathrm{x}} \mathrm{Mn}_{\mathrm{x}} \mathrm{Bi}_{2} \mathrm{Cl}_{12}$ Phosphors
}

\author{
Brenda Vargas, ${ }^{\dagger}$ Eduardo Coutiño-Gonzalez, ${ }^{\perp}$ Oscar Ovalle-Encinia, ${ }^{\ddagger}$ Citlali Sánchez-Aké,` ${ }^{\star}$ and \\ Diego Solis-Ibarra ${ }^{*}$
}

† Instituto de Investigaciones en Materiales, Universidad Nacional Autónoma de México, CU, Coyoacán, 04510, Ciudad de México, México

E-mail: diego.solis@unam.com

${ }^{\perp}$ Centro de Investigaciones en Óptica, A. C., Loma del Bosque 115, Colonia Lomas del Campestre, León, Guanajuato, 37150, México

‡ School for Engineering of Matter, Transport and Energy, Arizona State University, Tempe, AZ 85260, USA

^ Instituto de Ciencias Aplicadas y Tecnología, Universidad Nacional Autónoma de México, CU, Coyoacán, 04510,

Ciudad de México, México

\begin{abstract}
Layered halide perovskites and double perovskites optoelectronic properties have recently been the subject of intense research. Layered double perovskites represent the merging of both worlds, and as such, have the potential to further expand the already vast space of optoelectronic properties and applications of halide perovskites. Despite having more than 40 known members, to date, only the $<111>$-oriented layered double perovskites: $\mathrm{Cs}_{4} \mathrm{Cd}_{1-\mathrm{x}} \mathrm{Mn}_{\mathrm{x}} \mathrm{Bi}_{2} \mathrm{Cl}_{12}$, have shown efficient photoluminescence (PL). In this work, we replaced Bi with Sb to further investigate the electronic structure and PL properties of these materials, resulting in two new families of layered inorganic perovskites alloys with full solubility. The first family, $\mathrm{Cs}_{4} \mathrm{Cd}_{1-\mathrm{x}} \mathrm{MnSb}_{2} \mathrm{Cl}_{12}$, exhibits a PL emission at $605 \mathrm{~nm}$ ascribed to $\mathrm{Mn}^{2+}$ centers in octahedral coordination, and a maximum photoluminescence quantum yield PLQY of $28.5 \%$. The second family of alloys, also with full solubility, $\mathrm{Cs}_{4} \mathrm{Cd}_{0.8} \mathrm{Mn}_{0.2}\left(\mathbf{S b}_{1-}\right.$ $\left.{ }_{\mathrm{y}} \mathbf{B i}_{\mathrm{y}}\right)_{2} \mathrm{Cl}_{12}$, contains a fixed amount of $\mathrm{Mn}^{2+}$ and $\mathrm{Cd}^{2+}$ cations but different concentrations of the trivalent metals. This variability allows the tuning of the PL emission from $603 \mathrm{~nm}$ to $614 \mathrm{~nm}$. We show that the decreased efficiency of the $\mathrm{Cs}_{4} \mathrm{Cd}_{1-}$ ${ }_{x} \mathrm{Mn}_{x} \mathrm{Sb}_{2} \mathrm{Cl}_{12}$ family compared to $\mathrm{Cs}_{4} \mathrm{Cd}_{1-x} \mathrm{Mn}_{x} \mathrm{Bi}_{2} \mathrm{Cl}_{12}$, is mostly due to a decreased spin-orbit coupling in $\mathrm{Sb}$ and the subsequent increased electronic delocalization compared to the Bi alloys, reducing the energy transfer to $\mathrm{Mn}^{2+}$ centers. This work lays out a roadmap to understand and achieve high photoluminescence efficiencies in layered double perovskites.
\end{abstract}

The positioning of halide perovskites as the next highperformance semiconductors was possible thanks to their remarkable optoelectronic properties such as small bandgaps, disperse bands and weak exciton binding energies. Despite such benevolent properties, the toxicity of lead and long term-stability have raised some concerns. ${ }^{1}$ An alternative to tackle the latter problem is to reduce the dimensionality of the perovskites by inserting hydrophobic cations that also modify the physical and electronic properties of the materials allowing a wider variety of compositions and properties. ${ }^{2-4}$ An approach to tackle the toxicity of $\mathrm{Pb}$ is to replace it through an heterovalent substitution, which renders an elpasolite structure or double perovskite. ${ }^{5}$ The combination of both strategies, dimensional reduction and heterovalent substitution, expands even further the already prolific halide perovskite realm. Further, structural and electronic dimensional reduction in these materials produces quantum confinement in bulk solids without the need of nanostructure synthesis protocols and, contrary to their 3D counterparts, they exhibit larger bandgaps, less dispersive bands and high exciton binding energies. ${ }^{2,3,6}$ These properties have been exploited for luminescent applications in nonlinear optical processes, ${ }^{7-9}$ LEDs, ${ }^{10}$ among others.

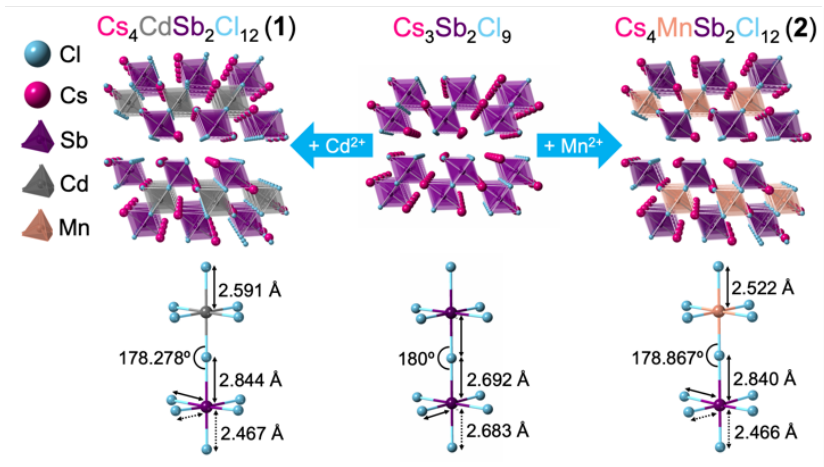

Figure 1. Top: crystal structures of $\mathrm{Cs}_{4} \mathrm{CdSb}_{2} \mathrm{Cl}_{12}, \mathrm{Cs}_{3} \mathrm{Sb}_{2} \mathrm{Cl}_{9}$, and $\mathrm{Cs}_{4} \mathrm{MnSb}_{2} \mathrm{Cl}_{12}$. Bottom: the equatorial, axial bond lengths and $\mathrm{Mn}-\mathrm{Cl}-\mathrm{Sb}$ angle in the corresponding octahedra. 
A)

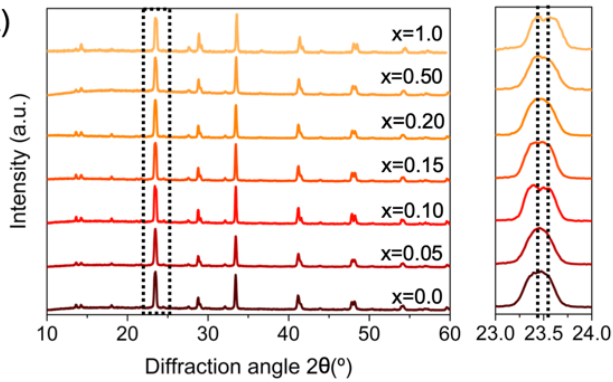

B)

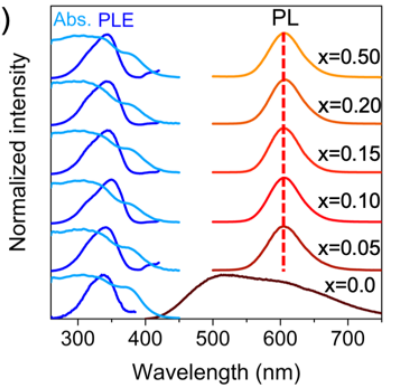

C)

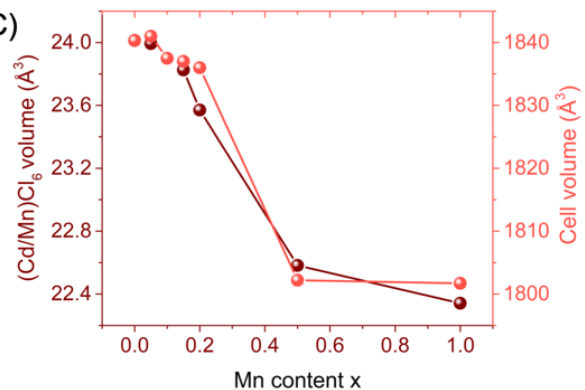

Figure 2. A) PXRD diffractograms of the $\mathrm{Cs}_{4} \mathrm{Cd}_{1-\mathrm{x}} \mathrm{Mn}_{\mathrm{x}} \mathrm{Sb}_{2} \mathrm{Cl}_{12}$ family of $<111>$-oriented layered perovskites with increasing Mn content $\mathrm{x}$, and B) UV-Vis diffuse reflectance measurements converted to pseudo-absorbance, PL and PLE spectra for increasing Mn content, C) $(\mathrm{Cd} / \mathrm{Mn}) \mathrm{Cl}_{6}$ and cell volumes decreased with increasing Mn content.

Conceptually, layered perovskites are derived by slicing the 3D framework in a crystallographic direction. ${ }^{2}$ Experimentally, this can be achieved by incorporating a large organic cation that separates the inorganic layers or by replacing $\mathrm{Pb}^{2+}$ with a metal in a different oxidation state, such as $\mathrm{Bi}^{3+}$ or $\mathrm{Sb}^{3+}$. The charge difference is compensated by the generation of ordered vacancies throughout the lattice, which results in a layered perovskite structure

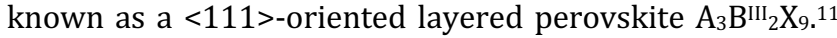
The thickness of the inorganic sheets can be increased with a heterovalent replacement of the trivalent metal by two metals, $\mathrm{M}^{\prime I I}$ and $\mathrm{M}^{\mathrm{III}}$, yielding the triple-layer structure $\mathrm{A}_{4} \mathrm{M}^{\prime}{ }^{\prime I} \mathrm{M}^{\mathrm{III}} \mathrm{X}_{12}\left(\mathrm{M}=\mathrm{Bi}^{3+}, \mathrm{Sb}^{3+} ; \mathrm{M}^{\prime}=\mathrm{Cd}^{2+}, \mathrm{Mn}^{2+}, \mathrm{Cu}^{2+}\right)$ or a layered double perovskite, where one layer of $\mathrm{M}^{\prime \prime I} \mathrm{Cl}_{6}$ octahedra alternates with two layers of $\mathrm{M}^{\mathrm{II}} \mathrm{Cl}_{6}$ octahedra. ${ }^{12}$ In $\mathrm{Pb}$ and $\mathrm{Sn}$ halide perovskites, the optical properties show a significant and systematic variation with the thickness of the sheet $n \cdot{ }^{13}$ In the $<111>$-oriented layered perovskites, $n$ can be modulated by changing the metals in the structure. This metal substitution drastically changes the optical and electronic properties of the materials giving rise to a broad range of applications, from absorbers in solar cells, ${ }^{12,14}$ phosphors, ${ }^{15}$ photodetectors, ${ }^{16-18}$ and spintronics. ${ }^{19-21}$

Recently, a new family of crystalline solid solutions was reported: $\mathrm{Cs}_{4} \mathrm{Cd}_{1-\mathrm{x}} \mathrm{Mn}_{\mathrm{x}} \mathrm{Bi}_{2} \mathrm{Cl}_{12}(\mathrm{x}=0$ - 1), with a PL emission centered at $595 \mathrm{~nm}$ ascribed to the parity and spin forbidden ${ }^{4} \mathrm{~T}_{1}(\mathrm{G}) \rightarrow{ }^{6} \mathrm{~A}_{1}(\mathrm{~S})$ transition of octahedrally coordinated $\mathrm{Mn}^{2+}$ ions. ${ }^{15}$ Later, we reported an improved PLQY of 79.5\% with a Mn content of $10 \%(x=0.10)$, attributed to a favorable energy band alignment and the low dimensional nature of the perovskites that enhances an efficient energy transfer from the host to $\mathrm{Mn}^{2+}$ ions. ${ }^{22}$ Woodward and coworkers proposed that the $\left[\mathrm{BiCl}_{6}\right]^{3-}$ octahedra in the structure act as sensitizers that transfer the energy to $\mathrm{Mn}^{2+}$ recombination sites. The incorporation of $\mathrm{Cd}^{2+}$ electronically isolates $\mathrm{Mn}-\mathrm{Bi}-\mathrm{Mn}$ networks increasing radiative recombination in $\mathrm{Mn}^{2+}$ sites. ${ }^{15}$ To date, this is the only family of layered double perovskites that displays efficient PLQY.,313,23

The family of solid solutions $\mathrm{Cs}_{4} \mathrm{Cd}_{1-\mathrm{x}} \mathrm{Mn}_{\mathrm{x}} \mathrm{Bi}_{2} \mathrm{Cl}_{12}$, proved to be chemically stable with a highly efficient PL and interesting magnetic properties that could be harnessed in spin-electronics and spin-photonics applications..$^{20,24}$ Thus, we decided to explore the effects of substituting Bi by $\mathrm{Sb}$ in the materials optoelectronic properties. Herein, we report the optical and magnetic properties of a new family of solid solutions $\mathrm{Cs}_{4} \mathrm{Cd}_{1-\mathrm{x}} \mathrm{Mn}_{\mathrm{x}} \mathrm{Sb}_{2} \mathrm{Cl}_{12}$ with $\mathrm{x}$ spanning from 0 to 1 .
The materials present a PL emission centered at $605 \mathrm{~nm}$, ascribed to the $\mathrm{Mn}^{2+}$ centers, and a maximum PLQY of $28.5 \%$ for a $\mathrm{Mn}^{2+}$ content of $20 \%(\mathrm{x}=0.20)$. The drop in PLQY, compared to the $78.5 \%$ PLQY in the Bi materials, results from a less efficient energy transfer from $\mathrm{Sb}$ sensitizers to $\mathrm{Mn}^{2+}$ activators mostly due to the decreased spin-orbit coupling in $\mathrm{Sb}$ and the increased electronic delocalization. We also report the synthesis of Sb-Bi alloys, $\mathrm{Cs}_{4} \mathrm{Cd}_{0.8} \mathrm{Mn}_{0.2}\left(\mathbf{S b}_{1-y} \mathbf{B i}_{\mathrm{y}}\right)_{2} \mathrm{Cl}_{12}$, over the entire $y$ composition range from 0 to 1 . Furthermore, the mixed alloys allow the modulation of the PL emission maximum from $603 \mathrm{~nm}$ to $614 \mathrm{~nm}$ exhibiting a non-linear band gap variation that decreases the energy transfer to $\mathrm{Mn}^{2+}$ centers.

Replacing $\mathrm{Bi}^{3+}$ with $\mathrm{Sb}^{3+}$ in the solid solutions was the next natural step for several reasons: it allows to assess the role of the trivalent metal in the optical properties of the phosphors, expanding our understanding of the luminescent properties of layered double perovskites. Also, it is known that an efficient energy transfer from $\mathrm{Sb}^{3+}$ activators to $\mathrm{Mn}^{2+}$ sensitizers pairs can take place, which has been exploited in commercial phosphors such as $\left[3 \mathrm{Ca}_{3}\left(\mathrm{PO}_{4}\right)_{2} \mathrm{Ca}(\mathrm{F}, \mathrm{Cl})_{2}: \mathrm{Sb}^{3+}, \mathrm{Mn}^{2+}\right]$, and other host matrices. ${ }^{25-27}$ Thus, $\mathrm{Sb}^{3+}$ substitution could potentially lead to an improved luminescence.

In a previous work, the end members of the new $\mathrm{Cs}_{4} \mathrm{Cd}_{1-}$ ${ }_{x} \mathrm{Mn}_{\mathrm{x}} \mathbf{S b}_{2} \mathrm{Cl}_{12}$ family of solid solutions, $\mathrm{Cs}_{4} \mathrm{Cd}_{\mathbf{S b}} \mathbf{C b}_{12}$ (1) and $\mathrm{Cs}_{4} \mathrm{MnSb}_{2} \mathrm{Cl}_{12}$ (2), were prepared by precipitation of the respective metallic salts in concentrated hydrochloric acid. ${ }^{28,29}$ Despite the ionic radii difference between $\mathrm{Cd}^{2+}$ and $\mathrm{Mn}^{2+}$, both powders crystallize in the same trigonal $R \overline{3} \mathrm{~m}$ structure. As expected, the intermediate solid solutions can also be synthesized by this method (see SI) to obtain whitish powders with a light yellow or pink tone for the Mn-only compound. Analysis of powder X-ray diffraction (PXRD) data indicates that intermediate materials are pure and isostructural to the end members (Figure 2A). $\mathrm{Mn}$ is effectively incorporated in the structure as confirmed by the slight shift to higher diffraction angles that originates from the incorporation of the smaller cation $\mathrm{Mn}^{2+}$ in $\mathrm{Cd}^{2+}$ sites, and by the decrease of the cell and $\left(\mathrm{Cd}_{1-\mathrm{x}} / \mathrm{Mn}_{\mathrm{x}}\right) \mathrm{Cl}_{6}$ octahedra volumes (Figure 2C), obtained from Rietveld refinements (Table S2). Inductively Couple Plasma-Optical Emission Spectroscopy (ICP-OES) analysis indicates that the nominal content of $\mathrm{Mn}$ almost perfectly matches the actual $\mathrm{Mn}^{2+}$ content in the samples (Table S2), allowing an optimal control of $\mathrm{Mn}$ incorporation in these materials. 
A)

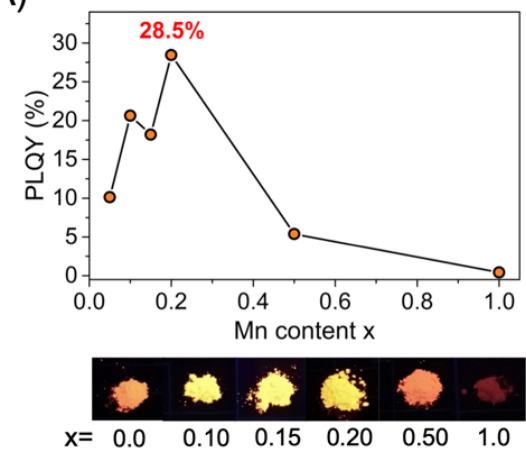

B)

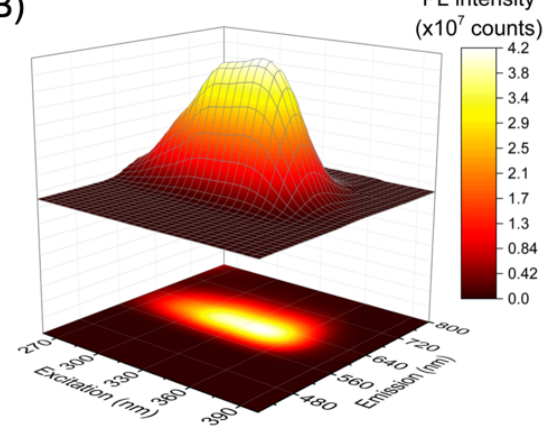

C)

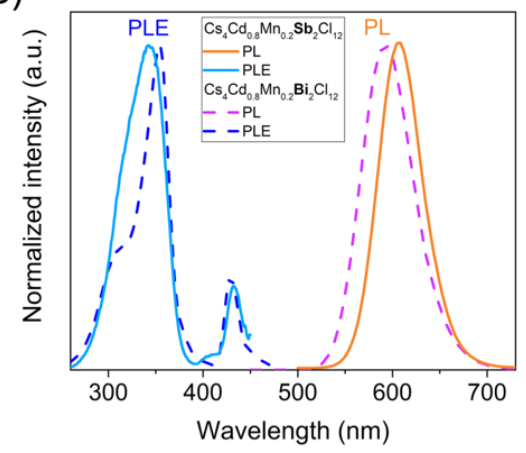

Figure 3. A) PLQY as a function of $\mathrm{Mn}^{2+}$ content for the family of materials $\mathrm{Cs}_{4} \mathrm{Cd}_{1-\mathrm{x}} \mathrm{Mn}_{\mathrm{x}} \mathrm{Sb}_{2} \mathrm{Cl}_{12}$, B) photo-excitation 3D mapping of $\mathrm{Cs}_{4} \mathrm{Cd}_{0.8} \mathrm{Mn}_{0.2} \mathbf{S b}_{2} \mathrm{Cl}_{12}$ and, C) comparison between PLE and PL spectra of $\mathrm{Cs}_{4} \mathrm{Cd}_{0.8} \mathrm{Mn}_{0.2} \mathbf{S b}_{2} \mathrm{Cl}_{12}$ and $\mathrm{Cs}_{4} \mathrm{Cd}_{0.8} \mathrm{Mn}_{0.2} \mathbf{B i}_{2} \mathrm{Cl}_{12}$.

Thermogravimetric analysis shows that the materials are stable up to $265^{\circ} \mathrm{C}$ (Figure S1)..$^{28,29}$

Distortions in the $\mathrm{M}^{\mathrm{II}} \mathrm{Cl}_{6}$ octahedra can play an important role in these structures and a method to measure them is with the quadratic elongation and variance of octahedral angles (see Table S3). ${ }^{30}$ The $\mathrm{SbCl}_{6}$ octahedra in $\mathrm{Cs}_{3} \mathrm{Sb}_{2} \mathrm{Cl}_{9}$ are almost perfect (Figure 1), only presenting a slight variance in the angle bond. However, a larger variance of the octahedral angles in the $\mathrm{M}^{\mathrm{III}} \mathrm{Cl}_{6}$ octahedra was observed in the $\mathrm{Cd}$-containing structures, $\mathrm{Cs}_{4} \mathrm{CdSb}_{2} \mathrm{Cl}_{12}$ and $\mathrm{Cs}_{4} \mathrm{CdBi}_{2} \mathrm{Cl}_{12}$ (Table S3). On the other hand, $\mathrm{MnCl}_{6}$ and $\mathrm{CdCl}_{6}$ form perfect octahedra in both structures, with bond lengths of $\mathrm{Mn}-\mathrm{Cl}=$ $2.522 \AA$ and $\mathrm{Cd}-\mathrm{Cl}=2.591 \AA$, respectively.

First, we analyzed the optical absorption of the samples with increasing $\mathrm{Mn}^{2+}$ content (Figure 2B). All samples display a single broad absorption band with a maximum at $\sim 310 \mathrm{~nm}$ likely associated with the spin-forbidden ${ }^{1} \mathrm{~S}_{0} \rightarrow{ }^{3} \mathrm{P}_{1}$ transition of the $\mathrm{SbCl}_{6}$ octahedra, ${ }^{31,32}$ and an absorption edge that redshifts approximately $15 \mathrm{~nm}$ from the $\mathrm{Cd}$-pure compound to the $\mathrm{Mn}$-pure compound. Unlike their $\mathrm{Bi}^{3+}$ analogues, optical absorption from $d-d \mathrm{Mn}^{2+}$ transitions, ${ }^{4} \mathrm{~T}_{1}(\mathrm{G}) \rightarrow{ }^{6} \mathrm{~A}_{1}(\mathrm{~S})$ and ${ }^{4} \mathrm{~T}_{2}(\mathrm{G}) \rightarrow{ }^{6} \mathrm{~A}_{1}(\mathrm{~S})$, were not observed (see absorbance comparison of both families in Figure S4).

All Mn-containing materials present a PL emission centered at $606 \mathrm{~nm}$ with a FWHM of $58 \mathrm{~nm}$ with similar features and shapes (Figure 2B). The emission comes from the spin and parity forbidden ${ }^{4} \mathrm{~T}_{1}(\mathrm{G}) \rightarrow{ }^{6} \mathrm{~A}_{1}(\mathrm{~S})$ transition of

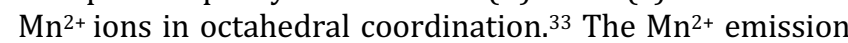
is slightly different from the emission of the Bi materials, which is centered at $595 \mathrm{~nm}$ (Figure 3C). The volume of the $\mathrm{MnCl}_{6}$ octahedra in structure 2 is $21.38 \AA^{3}$ (Figure 1 ), which is slightly smaller than the same octahedra in the $\mathrm{Bi}$ materials (21.49 $\AA^{3}$ ). As a consequence, the transition energy between the ${ }^{4} \mathrm{~T}_{1}$ and ${ }^{6} \mathrm{~A}_{1}$ levels decreases due to an increased crystal field strength and thus, shifts the emission to longer wavelengths. ${ }^{34}$ The PL spectrum of structure $\mathbf{1}$ is quite different from the samples that contain $\mathrm{Mn}^{2+}$ (Figure 2B); the emission is very broad with a full width at halfmaximum (FWHM) of $220 \mathrm{~nm}$ and very low intensity. This kind of emission has been ascribed to self-trapped excitons (STEs) in similar materials. ${ }^{35}$ The maximum PLQY of $28.5 \%$ is reached at $\mathrm{x}=0.20$ (Figure $3 \mathrm{~A}$ ). This efficiency is higher than other Mn-doped double halide perovskites and in the same order as some Mn-doped layered halide perovskites. $^{36-39}$ The PL emissions with excitations wavelengths from 300 to $380 \mathrm{~nm}$ (Figure S2) and the photoexcitation 3D plot (Figure 3B, S8) indicate that the emission comes from the same excited level as all excitation wavelengths produce the same emission profile. Interestingly, the band at $440 \mathrm{~nm}$ corresponding to the ${ }^{6} \mathrm{~A}_{2}(\mathrm{~S}) \rightarrow{ }^{4} \mathrm{~T}_{2}(\mathrm{G})$ transition of $\mathrm{Mn}^{2+}$ ions in the PLE spectra does not appear in the absorption spectra (Figure 2B and Figure 3C). The PL and PLE features of Sb and Bi are very similar (Figure 3C) suggesting that the emission mechanism is very similar in both families of perovskites.

We studied the magnetic coupling in $\mathrm{Cs}_{4} \mathrm{Cd}_{1-\mathrm{x}} \mathrm{Mn}_{\mathrm{x}} \mathbf{S b}_{2} \mathrm{Cl}_{12}$ with electron paramagnetic resonance (EPR). Generally, in this type of systems, one would expect that as $\mathrm{Mn}^{2+}$ concentration increases, the distance between neighboring $\mathrm{Mn}^{2+}$ ions decreases, allowing adjacent $\mathrm{Mn}^{2+}$ to become magnetically coupled with each other. ${ }^{33}$ The EPR spectra for $x<0.50$ (Figure 4A, S10) show two features: a hyperfine structure originating from the interaction between the spin $(S=5 / 2)$ of the unpaired $3 d$ electrons and the $I=5 / 2$ spin of the ${ }^{55} \mathrm{Mn}$ nucleus, generally assigned to $\mathrm{Mn}^{2+}$ isolated ions, ${ }^{40}$ and a broad signal ascribed to coupled $\mathrm{Mn}^{2+}$ pairs. ${ }^{33}$ This behavior is similar to that observed in Bi-materials, albeit with an apparent weaker magnetic coupling in the Sbmaterials. The presence of isolated $\mathrm{Mn}^{2+}$ ions, and $\mathrm{Mn}-\mathrm{Mn}$ pairs was confirmed by the time-resolved photoluminescence (TRPL) curves which can be fitted with a bi-exponential function for $\mathrm{x}<0.5$ and tri-exponential function for $\mathrm{x}=0.50$. From the fitting, two decay lifetimes were obtained, one in the tenth of $\mu$ s, and the second in the order of ms, two order of magnitude slower (Figure 4B, S8 and Table S11). The slower decay lifetime is generally associated to isolated $\mathrm{Mn}^{2+}$ ions and the faster decay lifetime to $\mathrm{Mn}-\mathrm{Mn}$ pairs as magnetic exchange relaxes the spin forbidden $d-d$ transitions of Mn ions. ${ }^{33}$ Further, for the $\mathrm{Bi}$ materials, the hyperfine structures are clearly visible only in the $\mathrm{Mn}$-diluted regime ( $\mathrm{x}=0.005)$ (Figure S8), whereas for the $\mathrm{Sb}$-materials, they are visible up to $\mathrm{x}=0.15$ despite having a shorter $\mathrm{Mn}-\mathrm{Mn}$ bond length, $7.477 \AA$ and $7.539 \AA$ for neighboring $\mathrm{Mn}$ ions, respectively. This is further confirmed by the time-resolved PL emission measurements, where the exponential amplitudes or decay lifetimes with increasing Mn content up to $\mathrm{x}=0.20$ (Table S11 and Figures 4B, S8, S10) remain constant. It is also worth noting that the decay lifetime of isolated $\mathrm{Mn}^{2+}$ ions is three times larger than that of Bi-materials (see Table S12), 
which also suggests a decreased exchange interaction between $\mathrm{Mn}^{2+}$ centers.

As predicted from theoretical calculations, ${ }^{28}$ the band alignment changes depending on whether $\mathrm{Sb}$ or $\mathrm{Bi}$ is incorporated into these layered perovskites. ${ }^{41}$ For example, a straightforward consequence of the trivalent metal substitution is that the $\mathrm{Sb}$ materials absorption edge is red shifted around $20 \mathrm{~nm}$ compared to Bi materials. However, the emission in Mn-doped materials is highly sensitive to the band edge position and band gap of the host, because both parameters affect the energy transfer to $\mathrm{Mn}^{2+}$ centers. Thus, we synthesized new solid solutions, $\mathrm{Cs}_{4} \mathrm{Cd}_{0.8} \mathrm{Mn}_{0.2}\left(\mathbf{S b}_{1-\mathrm{y}} \mathbf{B i}_{\mathrm{y}}\right)_{2} \mathrm{Cl}_{12}$ with different Bi contents $(y)$, which turn out to have full $\mathrm{Sb} / \mathrm{Bi}$ solubility in the $0-1$ range. We decided to incorporate $80 \% \mathrm{Cd}$ content to increase the PL intensity as both, $\mathrm{Bi}$ and $\mathrm{Sb}$ materials, show high PL efficiency for this $\mathrm{Cd} / \mathrm{Mn}$ ratio. This allowed us to tune the absorption band edge and to determine its effect on the energy transfer to $\mathrm{Mn}^{2+}$ ions. The PXRD patterns confirm single phases (Figure 5A). The absorbance spectra (Figure 5B) show that the doublet of the ${ }^{1} \mathrm{~S}_{0} \rightarrow{ }^{3} \mathrm{P}_{1}$ transition, which only appears in the Bi materials, emerges for a Bi content of $y>0.9$ along with a visible increase in PL intensity (Figure 5D). Interestingly, the absorption band edge shifts to longer wavelengths until $y=0.3$ and then shifts back to shorter wavelengths, a behavior known as band gap bowing (Figure 5B). ${ }^{42,43}$ This is further corroborated by the yellow tone that the intermediate materials develop with changing concentrations of the trivalent metals. With the incorporation of small amounts of $\mathrm{Bi}$ in $\mathrm{Cs}_{4} \mathrm{Cd}_{0.8} \mathrm{Mn}_{0.2} \mathbf{S b}_{2} \mathrm{Cl}_{12}$ $(y=0)$, the PL intensity drastically decreases (Figure S6), and the emission is shifted to shorter wavelengths from 614 to $603 \mathrm{~nm}$ as depicted in Figure 5C and 5D (see SI for more details on these measurements).
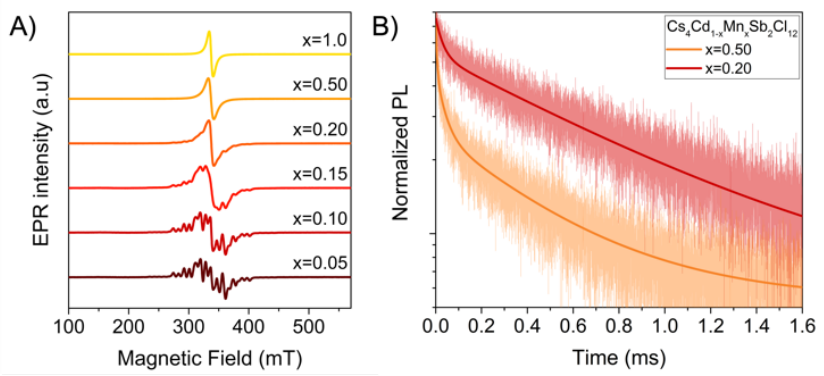

Figure 4. A) Room temperature electron paramagnetic resonance of $\mathrm{Cs}_{4} \mathrm{Cd}_{1-\mathrm{x}} \mathrm{Mn}_{\mathrm{x}} \mathrm{Sb}_{2} \mathrm{Cl}_{12}$ and $\mathrm{B}$ ) time-resolved $\mathrm{PL}$ for $\mathrm{X}$ $=0.20$ and 0.50 .

The replacement of $\mathrm{Bi}$ with $\mathrm{Sb}$ in the materials drastically affects the PLQY, since the $\mathrm{Mn}^{2+}$ emission depends on the energy transfer from the photo-excited host to the $\mathrm{Mn}^{2+}$ centers and the subsequent radiative decay from $\mathrm{Mn}^{2+}$ centers, one or perhaps both processes could be affected by the trivalent metal substitution. Several factors could be affecting the efficiency of the energy transfer from host to dopant, for instance, Woodward and coworkers propose that the $\mathrm{Bi}$ materials absorb light through localized excitations of the $\mathrm{BiCl}_{6}$ octahedra and when returning to the ground state, they transfer the energy to the $\mathrm{Mn}^{2+}$ sites. ${ }^{36}$ Delocalized wavefunctions yield dispersive bands and give rise to broad optical transitions, which accounts for the broadening of the doublet ${ }^{1} \mathrm{~S}_{0} \rightarrow{ }^{3} \mathrm{P}_{1}$ band in the absorption spectra with increasing Mn content in the Bi-materials (see SI). ${ }^{13}$ The degeneracy of this spin-forbidden transition can be relaxed by spin-orbit coupling (SOC) and in some materials, ${ }^{44}$ as $\mathrm{Cs}_{4} \mathrm{Cd}_{1-\mathrm{x}} \mathrm{Mn}_{\mathrm{x}} \mathbf{B i}_{2} \mathrm{Cl}_{12}$ solid solutions, it can split into an asymmetric doublet resulting from a dynamic JahnTeller distortion. However, a single broad band is visible in the absorption spectra of $\mathrm{Cs}_{4} \mathrm{Cd}_{1-\mathrm{x}} \mathrm{Mn}_{\mathrm{x}} \mathbf{S b}_{2} \mathrm{Cl}_{12}$, which suggests that the spin-orbit and/or the Jahn-Teller coupling in $\mathrm{Sb}$ ions is not as strong as in the Bi-materials. Interestingly, the crystal symmetry of both the $\mathrm{Sb}$ and $\mathrm{Bi}$ families is not affected by the dynamic Jahn Teller dynamic as both conserve the $R \overline{3} m$ crystal group. This dynamic expression of the $n s^{2}$ lone pair while maintaining the longrange symmetry has been reported for other double perovskites. ${ }^{45}$ Since the SOC is not as strong in $\mathrm{Sb}$, the spinforbidden ${ }^{1} \mathrm{~S}_{0} \rightarrow{ }^{3} \mathrm{P}_{1}$ transitions cannot be relaxed, likely reducing the light absorption from the $\mathrm{SbCl}_{6}$ octahedra.

As previously mentioned, the band alignment of the host has a critical role in the energy transfer to $\mathrm{Mn}^{2+}$ centers. The band gap nonlinearity or bowing in tin/lead perovskites has been attributed to the energy mismatch between atomic orbitals that compose the valence and conduction bands and also to a small contribution from lattice strain resulting in a band gap that becomes lower than either end compounds. ${ }^{42}$ For $\mathrm{Cs}_{2} \mathrm{Ag}\left(\mathrm{Sb}_{\mathrm{x}} \mathrm{Bi}_{1-\mathrm{x}}\right) \mathrm{Br}_{6}$ alloys, $\mathrm{Z}$. Li and collaborators proposed a bowing originating from a type II gap alignment between the pure compounds, which allows the non-linear mixing of electronic states. ${ }^{46} \mathrm{~A}$ similar effect could be taking place in the Bi/Sb solid solutions (Figure 5). Importantly, the band edge absorption shift has a clear effect on the PL intensity; as it shifts to shorter wavelengths, the emission intensity increases (Figure S6). Although the band edge shift does not behave linearly, it depicts the drastic effect that it has on the PL intensity and therefore on the energy transfer to $\mathrm{Mn}^{2+}$. This result suggests that the substitution of $\mathrm{Bi}$ with $\mathrm{Sb}$ in the solid solutions is modifying the band alignment and decreasing the energy transfer to $\mathrm{Mn}^{2+}$ centers.

The decrease in PLQY is a consequence of the replacement of $\mathrm{Bi}$ orbitals with $\mathrm{Sb}$ orbitals in the band structure of these materials. DFT calculations of structures $\mathbf{1}$ and $\mathbf{2}$ were conducted in some previous work, ${ }^{28,29,47}$ giving us insights into the electronic structure of these perovskites. The valence band maximum (VBM) is composed of $\mathrm{Cd} 4 d / \mathrm{Cl} 3 p$ and $\mathrm{Sb} 5 s / \mathrm{Cl} 3 p$ sates and the conduction band minimum (CBM) of $\mathrm{Cd} 5 s / \mathrm{Cl} 3 p$ and $\mathrm{Cl}$ $3 p / \mathrm{Sb} 5 s$ states. Furthermore, it is known that the $3 p$ and $4 p$ orbital overlap of halides in $\mathrm{Cs}_{4} \mathrm{M}^{2+} \mathrm{B}^{3+}{ }_{2} \mathrm{X}_{12}$ is strong and that the $s$ orbitals of the trivalent metals are significantly more delocalized than $d$ orbitals leading to more dispersion in the valence band. ${ }^{47}$ According to Woodward, in the Bi alloys, the incorporation of $\mathrm{Cd}^{2+}$ contributes to electronically isolate $\mathrm{Mn}-\mathrm{Bi}-\mathrm{Mn}$ networks by decreasing the electronic dimensionality of the structure and increasing radiative recombination on $\mathrm{Mn}^{2+}$ sites. ${ }^{15}$ Furthermore, in some $\mathrm{Bi}$ materials, the relativistic contraction of the $6 s$ orbital results in a more localized, lower-energy valence s orbital, compared to $\mathrm{Sb} 5 s$ lone pair.45,46,48 This is further supported by the fact that the $\mathrm{Sb}$-materials band edge absorption is redshifted in comparison to the $\mathrm{Bi}$-materials, which is an exception to the typical trend of decreasing bandgap upon atomic substitution with heavier members from the same 
periodic group. ${ }^{46}$ Hoye and collaborators observed the same effect in $\mathrm{Cs}_{2} \mathrm{Ag}\left(\mathrm{Sb}_{\times} \mathrm{Bi}_{1-\mathrm{x}}\right) \mathrm{Br}_{6}$ alloys, which was attributed to a stronger interaction of the $\mathrm{Sb} 5 s^{2}$ lone pair with $\mathrm{Ag}$ and $\mathrm{Br}$ orbitals. In our case, the band gap contraction could be due to a slight better coupling of the $\mathrm{Sb}$ lone pair with the $\mathrm{Cl} p$ and Cd orbitals that constitute both the CB and VB, slightly increasing delocalization but decreasing the radiative recombination on $\mathrm{Mn}^{2+}$ sites. It is worth noting that according to $\mathrm{Xu}$ et al., the $\mathrm{Cd}$-materials exhibit an even parity in both the VBM and CBM so the optical transition between band edges are forbidden. This type of parity forbidden transitions can be partly allowed by distortions in the metal octahedra, which are slightly larger for the Bi materials (Table S3). This could also be a factor affecting light absorption by the trivalent metal. Overall, the replacement of $\mathrm{Bi}$ by $\mathrm{Sb}$ suggests a greater electronic delocalization likely reducing the radiative recombination at $\mathrm{Mn}^{2+}$ sites despite $\mathrm{Cd}^{2+}$ incorporation.
A)
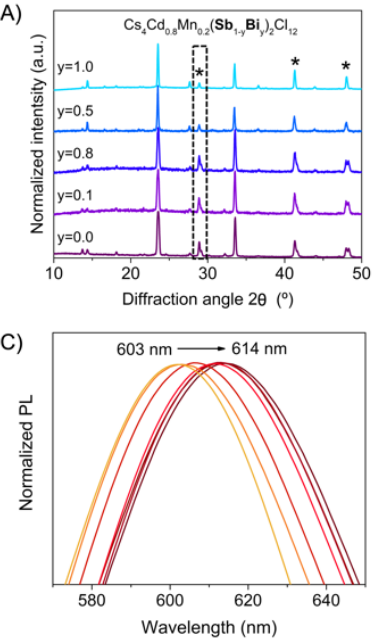

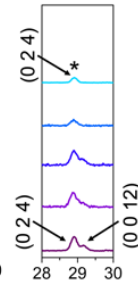

D)

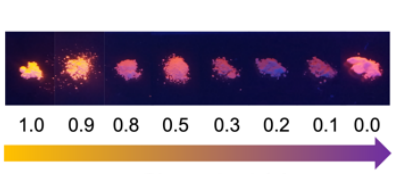

Sb content $(x)$

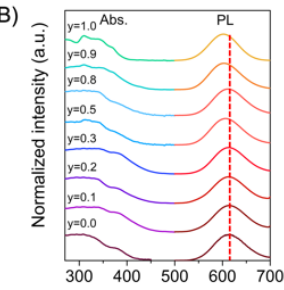

Wavelength $(\mathrm{nm})$
Figure 5. A) PXRD patterns of $\mathrm{Cs}_{4} \mathrm{Cd}_{0.8} \mathrm{Mn}_{0.2}\left(\mathbf{S b}_{1-\mathrm{y}} \mathbf{B i}_{\mathrm{y}}\right)_{2} \mathrm{Cl}_{12}$ solid solutions, the inset shows the doublet at $29^{\circ}$ for $\mathrm{y}=0$ and the intensity decrease of the $\left(\begin{array}{lll}0 & 0 & 12\end{array}\right)$ diffraction peak. B) Absorbance and PL emission of $\mathrm{Cs}_{4} \mathrm{Cd}_{0.8} \mathrm{Mn}_{0.2}\left(\mathbf{S b}_{1-\mathrm{y}} \mathbf{B i}_{\mathrm{y}}\right)_{2} \mathrm{Cl}_{12}$ for $0<y<1$. C). Inset of PL emission spectra that shows the PL redshift with increasing Sb content. D) Visual PL emission with increasing $\mathrm{Sb}$ content.

Another element that affects the efficiency of $\mathrm{Mn}^{2+}$ radiative decay is the magnetic exchange between $\mathrm{Mn}^{2+}$ centers. In general, the formation of $\mathrm{Mn}-\mathrm{Mn}$ pairs is associated with the introduction of non-radiative recombination pathways that decrease the efficiency of $\mathrm{Mn}^{2+}$ radiative decay for large doping/substitution concentrations (known as concentration quenching), which explains the appearance of a third decay pathway in the TDPL spectra (Table 1). In the Bi materials, we proposed that the absorption bands corresponding to the spin and parity forbidden, ${ }^{6} \mathrm{~A}_{1}(\mathrm{~S}) \rightarrow{ }^{4} \mathrm{~T}_{1}(\mathrm{G})$ and ${ }^{6} \mathrm{~A}_{2}(\mathrm{~S}) \rightarrow{ }^{4} \mathrm{~T}_{2}(\mathrm{G})$ transitions, were partly allowed due to the magnetic coupling of $\mathrm{Mn}^{2+}$ pairs. In the $\mathrm{Sb}$ alloys, $\mathrm{Mn}^{2+}$ pairs are also magnetically coupled, as demonstrated by EPR results and previous susceptibility-temperature measurements that revealed an antiferromagnetic behavior in structure 2 (Figure 1), ${ }^{29}$ but because the magnetic exchange is not as strong as in the Bi-materials, $d-d$ transitions are absent in the absorption spectra. The $\mathrm{Mn}^{2+}$ concentration at which the maximum PLQY is attained ( $\mathrm{x}=0.10$ for the $\mathrm{Bi}$-materials, and $\mathrm{x}=0.20$ for the $\mathrm{Sb}$-materials) differs because the magnetic exchange coupling between Mn centers in the Sbmaterials is lower thus, non-recombination pathways appear for larger $\mathrm{Mn}$ concentrations than in the Bimaterials. In general, when Mn concentration increases the PL emission shifts to longer wavelengths due to magnetic interactions. ${ }^{40}$ This is not the case for Sb materials, as PL emission remains constant at $605 \mathrm{~nm}$ throughout the entire range (Figure 2B). This is probably due to a long-range antiferromagnetic order via super-exchange interactions instead of a direct exchange coupling. ${ }^{49}$

In conclusion, we synthetized a new family of red-orange phosphors $\mathrm{Cs}_{4} \mathrm{Cd}_{1-\mathrm{x}} \mathrm{Mn}_{\mathrm{x}} \mathrm{Sb}_{2} \mathrm{Cl}_{12}$ with a maximum PLQY of $28.5 \%$. We propose that the replacement of Bi orbitals by $\mathrm{Sb}$ orbitals in the valence and conduction bands improves orbital interaction which leads to electronic delocalization decreasing the energy transfer to $\mathrm{Mn}^{2+}$ centers. Further, the reduced SOC in $\mathrm{Sb}$ and the band realignment are also elements that affect the energy transfer to $\mathrm{Mn}^{2+}$ centers. We also demonstrated that metal alloying on the $\mathrm{M}^{3+}$ site is possible in these layered double perovskites, which allows further modulation of the optoelectronic properties. Overall, this work creates an opening to study the intriguing optoelectronic properties of this emerging family of layered double perovskites.

\section{ASSOCIATED CONTENT}

\section{Supporting Information}

The Supporting Information is available free of charge on the ACS Publications website.

Complete experimental details (PDF)

\section{AUTHOR INFORMATION}

\section{Corresponding Author}

*E-mail: diego.solis@unam.mx.

ORCID Diego Solis-Ibarra: 0000-0002-2486-0967

\section{Funding Sources}

The authors thank funding from PAPIIT IA202418 and CONACYT's CB-A1-S-8729 \& CB-A1-S-44458.

\section{ACKNOWLEDGEMENTS}

We thank Carlos Ramos, Adriana Tejeda, Eriseth Morales, Lázaro Huerta, Alberto López, Alejandro Pompa, Cain González, Virginia Gómez and Miguel Angel Canseco for technical assistance. We also acknowledge M. Sc. Javier Tadeo Leon from the spectroscopy laboratory LANGEM-Instituto de Geología UNAM for the ICP analysis. B.V. acknowledges the support from CONACYT scholarship (Grant No. 270518).

\section{REFERENCES}

(1) Stoumpos, C. C.; Cao, D. H.; Clark, D. J.; Young, J.; Rondinelli, J. M.; Jang, J. I.; Hupp, J. T.; Kanatzidis, M. G. Ruddlesden-Popper Hybrid Lead Iodide Perovskite 2D Homologous Semiconductors. Chem. Mater. 2016, 28, 28522867.

Smith, I. C.; Hoke, E. T.; Solis-Ibarra, D.; McGehee, M. D.; Karunadasa, H. I. A Layered Hybrid Perovskite Solar-Cell Absorber with Enhanced Moisture Stability. Angew. Chemie - Int. Ed. 2014, 53, 11232-11235. 

Karunadasa, H. I. Layered Halide Double Perovskites: Dimensional Reduction of $\mathrm{Cs}_{2} \mathrm{AgBiBr}_{6}$. J. Am. Chem. Soc. 2018, 140, 5235-5240.

(4) Ortiz-Cervantes, C.; Carmona-Monroy, P.; Solis-Ibarra, D. Two-Dimensional Halide Perovskites in Solar Cells: 2D or Not 2D? ChemSusChem 2019, 12, 1560-1575.

(5) Igbari, F.; Wang, Z. K.; Liao, L. S. Progress of Lead-Free Halide Double Perovskites. Adv. Energy Mater. 2019, 9, 132.

(6) Almutlaq, J.; Yin, J.; Mohammed, O. F.; Bakr, O. M. The Benefit and Challenges of Zero-Dimensional Perovskites. $J$. Phys. Chem. Lett. 2018, 9, 4131-4138.

(7) Trujillo-Hernández, K.; Rodríguez-López, G.; Espinosa-Roa, A.; González-Roque, J.; Gómora-Figueroa, A. P.; Zhang, W.; Halasyamani, P. S.; Jancik, V.; Gembicky, M.; Pirruccio, G.; Solis-Ibarra, D. Chirality Control in White-Light Emitting 2D Perovskites. J. Mater. Chem. C 2020, 8, 9602-9607.

(8) Xu, J.; Li, X.; Xiong, J.; Yuan, C.; Semin, S.; Rasing, T.; Bu, X. H. Halide Perovskites for Nonlinear Optics. Adv. Mater. 2020, 32, 1-13.

(9) Han, X.; Zheng, Y.; Chai, S.; Chen, S.; Xu, J. 2D OrganicInorganic Hybrid Perovskite Materials for Nonlinear Optics. Nanophotonics 2020, 9, 1-24.

(10) Zhang, X.; Wang, C.; Zhang, Y.; Zhang, X.; Wang, S.; Lu, M.; Cui, H.; Kershaw, S. V.; Yu, W. W.; Rogach, A. L. Bright Orange Electroluminescence from Lead-Free TwoDimensional Perovskites. ACS Energy Lett. 2019, 4, 242248.

(11) Saparov, B.; Mitzi, D. B. Organic-Inorganic Perovskites: Structural Versatility for Functional Materials Design. Chem. Rev. 2016, 116, 4558-4596.

(12) Vargas, B.; Ramos, E.; Pérez-Gutiérrez, E.; Alonso, J. C.; Solis-Ibarra, D. A Direct Bandgap Copper-Antimony Halide Perovskite. J. Am. Chem. Soc. 2017, 139, 9116-9119.

(13) Connor, B. A.; Biega, R.-I.; Leppert, L.; Karunadasa, H. I. Dimensional Reduction of the Small-Bandgap Double Perovskite $\mathrm{Cs}_{2} \mathrm{AgTlBr}_{6}$. Chem. Sci. 2020, 11, 7708-7715.

(14) Saparov, B.; Hong, F.; Sun, J. P.; Duan, H. S.; Meng, W.; Cameron, S.; Hill, I. G.; Yan, Y.; Mitzi, D. B. Thin-Film Preparation and Characterization of $\mathrm{Cs}_{3} \mathrm{Sb}_{2} \mathrm{I}_{9}$ : A Lead-Free Layered Perovskite Semiconductor. Chem. Mater. 2015, 27, 5622-5632.

(15) Holzapfel, N. P.; Majher, J. D.; Strom, T. A.; Moore, C. E.; Woodward, P. M. Cs4Cd ${ }_{1-x} \mathrm{MnxBi}_{2} \mathrm{Cl}_{12}-\mathrm{A}$ Vacancy-Ordered Halide Perovskite Phosphor with High-Efficiency OrangeRed Emission. Chem. Mater. 2020, 32, 3510-3516.

(16) Cai, T.; Shi, W.; Hwang, S.; Kobbekaduwa, K.; Nagaoka, Y.; Yang, H.; Hills-kimball, K.; Zhu, H.; Wang, J.; Wang, Z.; Liu, Y.; Su, D.; Gao, J.; Chen, O. Lead-Free $\mathrm{Cs}_{4} \mathrm{CuSb}_{2} \mathrm{Cl}_{12}$ Layered Double Perovskite Nanocrystals. J. Am. Chem. Soc. 2020, 142, 11927-11936.

(17) Jayasankar, P. M.; Pathak, A. K.; Madhusudanan, S. P.; Murali, S.; Batabyal, S. K. Double Perovskite $\mathrm{Cs}_{4} \mathrm{CuSb}_{2} \mathrm{Cl}_{12}$ Microcrystalline Device for Cost Effective Photodetector Applications. Mater. Lett. 2020, 263, 127200.

(18) Wang, X. D.; Miao, N. H.; Liao, J. F.; Li, W. Q.; Xie, Y.; Chen, J.; Sun, Z. M.; Chen, H. Y.; Kuang, D. Bin. The Topdown Synthesis of Single-Layered $\mathrm{Cs}_{4} \mathrm{CuSb}_{2} \mathrm{Cl}_{12}$ Halide Perovskite Nanocrystals for Photoelectrochemical Application. Nanoscale 2019, 11, 5180-5187.

(19) Han, D.; Zhang, T.; Chen, S. High-Throughput FirstPrinciples Screening of Layered Magnetic Double Perovskites $\mathrm{Cs}_{4} \mathrm{MSb}_{2} \mathrm{X}_{12}$ for Spintronic Applications. J. Phys. Condens. Matter 2019, 32, 0-27.

(20) Tran, T. T.; Pocs, C. A.; Zhang, Y.; Winiarski, M. J.; Sun, J.; Lee, M.; Mcqueen, T. M.; Nat, O. R. Spinon Excitations in the Quasi-1D S = 1/2 Chain $\mathrm{Cs}_{4} \mathrm{CuSb}_{2} \mathrm{Cl}_{12}$. Phys. Rev. B 2020, $101,235107$.

(21) Singhal, N.; Chakraborty, R.; Ghosh, P.; Nag, A. LowBandgap $\mathrm{Cs}_{4} \mathrm{CuSb}_{2} \mathrm{Cl}_{12}$ Layered Double Perovskite:
Synthesis, Reversible Thermal Changes, and Magnetic Interaction. Chem. - An Asian J. 2018, 13, 2085-2092.

Vargas, B.; Reyes-Castillo, D. T.; Coutino-Gonzalez, E.; Ramos, C.; Sánchez-Aké, C.; Ciro, F.; Solis-Ibarra, D. Enhanced Luminescence and Mechanistic Studies on MnDoped Double Layered Perovskite Phosphors: $\mathrm{Cs}_{4} \mathrm{Mn}_{1-\mathrm{x}} \mathrm{Cd}_{\mathrm{x}} \mathrm{Bi}_{2} \mathrm{Cl}_{12}$. ChemRxiv 2020 .

(23) Jana, M. K.; Janke, S. M.; Dirkes, D. J.; Dovletgeldi, S.; Liu, C.; Qin, X.; Gundogdu, K.; You, W.; Blum, V.; Mitzi, D. B. Direct-Bandgap 2D Silver-Bismuth Iodide Double Perovskite: The Structure-Directing Influence of an Oligothiophene Spacer Cation. J. Am. Chem. Soc. 2019, 141, 7955-7964.

(24) Beaulac, R.; Archer, P. I.; Ochsenbein, S. T.; Gamelin, D. R. $\mathrm{Mn}^{2+}-$ Doped CdSe Quantum Dots: New Inorganic Materials for Spin-Electronics and Spin-Photonics. Adv. Funct. Mater. 2008, 18, 3873-3891.

(25) Solid State Luminescence, First edit.; Kitai, A. H., Ed.; Springer-Science+Business Media, B.V., 1993; Vol. 548.

(26) Chen, L.; Deng, X.; Xue, S.; Bahader, A.; Zhao, E.; Mu, Y.; Tian, H.; Lü, S.; Yu, K.; Jiang, Y.; Chen, S.; Tao, Y.; Zhang, $\mathrm{W}$. The Energy Transfer in the $\mathrm{Sb}^{3+}$ and $\mathrm{Eu}^{3+} \mathrm{Co}-$ Activated $\mathrm{YBO}_{3}$ Phosphor and Their White Luminescence for Deep Ultraviolet LEDs Application. J. Lumin. 2014, 149, 144-149. Blasse, G.; Bril, A. Study of Energy Transfer from $\mathrm{Sb}^{3+}, \mathrm{Bi}^{3+}$, $\mathrm{Ce}^{3+}$ to $\mathrm{Sm}^{3+}, \mathrm{Eu}^{3+}, \mathrm{Tb}^{3+}, \mathrm{Dy}^{3+}$. J. Chem. Phys. 1967, 47, 19201926.

(28) Vargas, B.; Torres-Cadena, R.; Reyes-Castillo, D. T.; Rodríguez-Hernández, J.; Gembicky, M.; MenéndezProupin, E.; Solis-Ibarra, D. Chemical Diversity in LeadFree, Layered Double Perovskites: A Combined Experimental and Computational Approach. Chem. Mater. 2020, 32, 424-429.

(29) Vargas, B.; Torres-Cadena, R.; Rodríguez-Hernández, J.; Gembicky, M.; Xie, H.; Jiménez-Mier, J.; Liu, Y. S.; Menéndez-Proupin, E.; Dunbar, K. R.; Lopez, N.; OlaldeVelasco, P.; Solis-Ibarra, D. Optical, Electronic, and Magnetic Engineering of $<111>$ Layered Halide Perovskites. Chem. Mater. 2018, 30, 5315-5321.

(30) Robinson, K.; Gibbs, G. V.; Ribbe, P. H. Quadratic Elongation: A Quantitative Measure of Distortion in Coordination Polyhedra. Science 1971, 172, 567-570.

(31) Oomen, E. W. J. L.; Smit, W. M. A.; Blasse, G. On the Luminescence of $\mathrm{Sb}^{3+}$ in $\mathrm{Cs}_{2} \mathrm{NaMCl}_{6}$ (with $\mathrm{M}=\mathrm{Sc}, \mathrm{Y}, \mathrm{La}$ ): A Model System for the Sutdy of Trivalent $\mathrm{s}^{2}$ Ions. J. Phys. C Solid State Phys. 1986, 19, 3263-3272.

(32) Li, J.; Tan, Z.; Hu, M.; Chen, C.; Luo, J.; Li, S.; Gao, L.; Xiao, Z.; Niu, G.; Tang, J. Antimony Doped $\mathrm{Cs}_{2} \mathrm{SnCl}_{6}$ with Bright and Stable Emission. Front. Optoelectron. 2019, 12, 352364.

(33) Yang, X.; Pu, C.; Qin, H.; Liu, S.; Xu, Z.; Peng, X. Temperature- and $\mathrm{Mn}^{2+}$ Concentration-Dependent Emission Properties of $\mathrm{Mn}^{2+}-$ Doped $\mathrm{ZnSe}$ Nanocrystals. J. Am. Chem . Soc. 2019, 141, 2288-2298.

(34) Fundamentals of Phosphors; William, M. Y., Shionoya, S., Yamamoto, H., Eds.; CRC Press, 2007.

(35) McCall, K. M.; Stoumpos, C. C.; Kostina, S. S.; Kanatzidis, M. G.; Wessels, B. W. Strong Electron-Phonon Coupling and Self-Trapped Excitons in the Defect Halide Perovskites $\mathrm{A}_{3} \mathrm{M}_{2} \mathrm{I}_{9}(\mathrm{~A}=\mathrm{Cs}, \mathrm{Rb} ; \mathrm{M}=\mathrm{Bi}, \mathrm{Sb})$. Chem. Mater. 2017, 29, $4129-4145$.

(36) Majher, J. D.; Gray, M. B.; Strom, T. A.; Woodward, P. M. $\mathrm{Cs}_{2} \mathrm{NaBiCl}_{6}: \mathrm{Mn}^{2+}-\mathrm{A}$ New Orange-Red Halide Double Perovskite Phosphor. Chem. Mater. 2019, 31, 1738-1744.

(37) Nandha K, N.; Nag, A. Synthesis and Luminiscence of MnDoped $\mathrm{Cs}_{2} \mathrm{AgInCl}_{6}$ Double Perovskite. ChemComm 2018, 54, 5205-5208.

(38) Cortecchia, D.; Mróz, W.; Neutzner, S.; Borzda, T.; Folpini, G.; Brescia, R.; Petrozza, A. Defect Engineering in 2D Perovskite by Mn(II) Doping for Light-Emitting Applications. Chem 2019, 5, 2146-2158.

(39) Locardi, F.; Cirignano, M.; Baranov, D.; Dang, Z.; Prato, M.; 
Drago, F.; Ferretti, M.; Pinchetti, V.; Fanciulli, M.; Brovelli, S.; De Trizio, L.; Manna, L. Colloidal Synthesis of Double Perovskite $\mathrm{Cs}_{2} \mathrm{AgInCl}_{6}$ and Mn-Doped $\mathrm{Cs}_{2} \mathrm{AgInCl}_{6}$ Nanocrystals. J. Am. Chem. Soc. 2018, 140, 12989-12995.

Lin, J.; Zhang, Q.; Wang, L.; Liu, X.; Yan, W.; Wu, T.; Bu, X.; Feng, P. Atomically Precise Doping of Monomanganese Ion into Coreless Supertetrahedral Chalcogenide Nanocluster Inducing Unusual Red Shift in $\mathrm{Mn}^{2+}$ Emission. J. Am. Chem . Soc. 2014, 136, 4769-4779.

(41) Lin, Y.-P.; Hu, S.; Xia, B.; Fan, K.-Q.; Gong, L.-K.; Kong, J.-T.; Huang, X.-Y.; Xiao, Z.; Du, K.-Z. Material Design and Optoelectronic Properties of Three-Dimensional Quadruple Perovskite Halides. J. Phys. Chem. Lett. 2019, 10, 52195225.

(42) Goyal, A.; McKechnie, S.; Pashov, D.; Tumas, W.; Schilfgaarde, M. Van; Stevanović, V. Origin of Pronounced Nonlinear Band Gap Behavior in Lead-Tin Hybrid Perovskite Alloys. Chem. Mater. 2018, 30, 3920-3928.

(43) Du, K. Z.; Meng, W.; Wang, X.; Yan, Y.; Mitzi, D. B Bandgap Engineering of Lead-Free Double Perovskite $\mathrm{Cs}_{2} \mathrm{AgBiBr}_{6}$ through Trivalent Metal Alloying. Angew. Chemie - Int. Ed.2017, 56, 8158-8162.
(44) Polák, K.; Mihóková, E. $\mathrm{In}^{+}, \mathrm{Pb}^{2+}$ and $\mathrm{Bi}^{3+}$ in $\mathrm{KBr}$ Crystal: Luminescence Dynamics. Opt. Mater. (Amst). 2010, 32, $1280-1282$.

(45) Mccall, K. M.; Morad, V.; Benin, B. M.; Kovalenko, M. V. Efficient Lone Pair-Driven Luminescence: StructureProperty Relationships in Emissive $5 \mathrm{~s}^{2}$ Metal Halides. ACS Mater. Lett. 2020, 2, 1218-1232.

(46) Li, Z.; Napari, M.; Palgrave, R. G.; Abdi-jalebi, M.; Andajigarmaroudi, Z.; Davies, D. W.; Laitinen, M.; Julin, J.; Richard, H.; Scanlon, D. O.; Walsh, A.; Hoye, R. L. Z. Bandgap Lowering in Mixed Alloys of $\mathrm{Cs}_{2} \mathrm{Ag}\left(\mathrm{Sb}_{\mathrm{x}} \mathrm{Bi}_{1-\mathrm{x}}\right) \mathrm{Br}_{6}$ Double Perovskite Thin Films. arXiv:2007.00388 [condmat.mtrl-sci] 2020, 1-29.

(47) Xu, J.; Liu, J.-B.; Wang, J.; Liu, B.-X.; Huang, B. Prediction of Novel $p$-Type Transparent Conductors in Layered Double Perovskites: A First-Principles Study. Adv. Funct. Mater. 2018, 28, 1800332.

(48) Pyykkö, P. Relativistic Effects in Structural Chemistry. Chem. Rev. 1988, 88, 563-594.

(49) Xu, J.; Xu, C.; Liu, J.-B. Prediction of Room-Temperature Half-Metallicity in Layered Halide Double Perovskites. $n p j$ Comput. Mater. 2019, 114. 